\title{
Externality-Correcting Taxes and Regulation
}

\section{IFS Working Paper W09/16}

Vidar Christiansen

Stephen Smith 


\title{
Externality-correcting taxes and regulation
}

\author{
Vidar Christiansen (University of Oslo)* \\ Stephen Smith (University College London and IFS)**
}

\begin{abstract}
Much of the literature on externalities has considered taxes and direct regulation as alternative policy instruments. Both instruments may in practice be imperfect, reflecting informational deficiencies and other limitations. We analyse the use of taxes and regulation in combination, to control externalities arising from individual consumption behaviour. We consider cases where taxes are either imperfectly differentiated to reflect individual differences in externalities, or where some consumption escapes taxation. In both cases we characterise the optimal instrument mix, and show how changing the level of direct regulation alters the optimal externality tax.
\end{abstract}

Keywords: externalities, Pigouvian taxes, regulations

JEL Classification numbers: $\mathrm{H} 21, \mathrm{H} 23$

Acknowledgments: Previous versions of the paper have been presented at the CESifo Area Conference on Public Sector Economics 2008, the 2008 EAERE conference in Gothenburg, the $65^{\text {th }}$ Congress of the IIPF in Maastricht, and the Nordic Workshop on Tax Policy and Public Economics 2008 in Uppsala. We are grateful to discussants and seminar participants and, in particular, to Tomas Sjögren and Jon Vislie for comments.

* Department of Economics, University of Oslo, P.O.Box 1095 Blindern, NO-0317 Oslo, Norway. Email: vidar.christiansen@econ.uio.no Fax: +4722855035 Phone: +4722 855121

** Department of Economics, University College London, Gower Street, London WC1E 6BT. Email stephen.smith@ucl.ac.uk. Phone +44 2076795882 


\section{Introduction}

Both taxes and direct regulation are used to discourage behaviour that gives rise to externalities. For example, most European countries levy significant taxes on cigarettes, and these are frequently justified in terms of the costs that cigarette smokers impose on others - including the ill-health and annoyance caused by passive smoking, and the costs of collectively-financed health care. In parallel, many countries have also introduced various forms of direct regulation with similar goals - such as the bans on smoking in workplaces and other public spaces introduced in recent years in Norway, Ireland, the UK and elsewhere. This paper looks at the economic issues which arise when externality taxes and direct regulation are used in parallel. When would the combined use of both instruments be justified in the sense of achieving outcomes which are better than could be achieved using one instrument alone? And what are the implications of changes in one instrument for the optimal level at which the other should be set? How, for example, does the introduction of an additional legal restriction on smoking affect the optimal level of the externality tax on cigarettes?

Most economic analysis of externality taxes and regulation has focussed on the two approaches as alternatives. In environmental policy, for example, economists have emphasised the efficiency advantages of using "market mechanisms" such as emissions taxes or tradable pollution permits compared with the traditional approach of direct "command-and-control" regulations requiring the use of particular production or abatement technologies, or setting limits on emissions. Sandmo (2000) expressed the conventional view of economists in the following words: "Economists have traditionally been sceptical about policy by persuasion, hostile to command and control policies and enthusiastic about market based instruments". Where polluters differ in costs of abatement, the flexibility offered by market mechanisms reduces the aggregate cost of achieving a given reduction in emissions compared with uniformly-applied regulation of abatement technologies or emissions levels. This argument is, however, underpinned by implicit assumptions about instrument imperfection. Under conditions of full information, costless implementation and certainty, an equivalent first-best outcome can be achieved by either command-and-control regulation, or a market mechanism. 
Information costs and asymmetries are central to the instrument choice debate. Regulated firms may know much more about the costs of changing pollution than the regulator, but will also have incentives not to reveal this information. $\mathrm{C} \& \mathrm{C}$ regulation may be compelled to treat firms the same when in fact they differ, while market mechanisms allow for differential responses.

Costs of information and monitoring also underlie the choice between various different forms that regulation can take. Compliance with bans, or with regulations mandating the installation of particular technologies, may be relatively cheap to monitor, which may account for much of the prevalence of these inflexible forms of regulation. Likewise, the operating costs of market mechanisms such as emissions taxes may influence the choice, and the design, of such instruments. Often it may be cheaper to tax emission proxies (such as the use of a particular input) than to tax measured emissions.

The upshot is that, in practice, the range of policy options available typically comprises a set of instruments characterised by various practical compromises. None of the available instruments is alone capable of implementing the first-best. We may want to ask which instrument gets closer to the first-best. But if both are sufficiently imperfect, we may also be interested in the properties of instrument combinations, in which two instruments are used to offset each others' weaknesses.

The literature on the economics of instrument combinations is much more limited than that on either/or instrument choice. Eskeland (1994) considers how an excise tax and regulation could be combined to mimic an otherwise-impracticable vehicle emissions fee. Innes (1996) models the effect on motor vehicle emissions of a wider range of instrument combinations. Hoel (1997) observes that the complexity of environmental problems, and the limitations of instrument design, typically mean that efficient regulation of road transport requires tax instruments to be combined with various other forms of regulation. Fullerton and Wolverton (1999) consider multi-part instruments, in which, typically, taxes and subsidies are combined to achieve an outcome closer to the first-best than either could alone. 
A parallel discussion concerns the relative merits of regulation by prices and by quantities. Weitzman (1974) showed that when there is uncertainty about the costs of pollution abatement the outcomes from regulation which sets a pollution price will differ from regulation which fixes the pollution quantity; the conditions under which one is superior to the other depend on the sensitivity of marginal abatement costs and marginal pollution damage to the emissions level. A case for combining elements of both approaches is made by Roberts and Spence (1976), who show that quantity regulation with upper and lower price "safety valves" can eliminate the extreme outcomes associated with pure price or quantity regulation. In a similar vein, Mandell (2004) has argued that when there is abatement cost uncertainty regulating some sectors by price and others by quantity may be preferable to uniform application of one or other approach to the whole economy.

In this paper we seek to characterise the circumstances in which combinations of tax and regulation may be required for efficient correction of some simple externality problems under conditions of certainty. The cases we consider all take the form of consumption externalities generated by individual consumption behaviour (although much of the underlying logic would also apply to externalities from production activities). We also basically confine our attention to situations where the purpose of taxation is to correct the externality; this allows us to abstract from the differences between taxes and direct regulation that reflect the value of the tax contribution to government revenues (the "double dividend" issue).

Our point of departure is the same as the literature on imperfect externality-correcting taxes (Sandmo, 1976, Green and Sheshinski, 1976), namely that the tax instruments available are somehow imperfect or inadequate. We consider situations where the available tax instruments can be supplemented with some form of direct regulation which is, likewise, imperfect, and therefore incapable alone of implementing the first-best. 
Following this introduction, the paper is in three main sections. In Section II we discuss the nature of the instrument imperfections which underpin the case for combined use of both tax and regulation. In Section III we consider cases where the tax instrument is incapable of differentiating efficiently between activities generating different levels of externality. For example, the tax on motor fuel cannot differentiate between fuel used to drive in congested road-space and fuel used for journeys which do not add to traffic congestion. We analyse the effect of combining direct regulation with the imperfect externality tax, and consider how direct regulation alters the optimal externality tax. In Section IV we then address an alternative source of imperfection, where the externality tax cannot be applied to all sources of the externality - for example, because some of the externality-generating goods can be purchased on the black market or imported without paying domestic tax. Again we consider the implications of adding direct regulation to the instrument mix. Section V briefly draws attention to some further issues largely neglected in the previous parts. Section VI draws some conclusions

\section{Imperfections in Taxes and Regulation}

In considering tax and regulation combinations we are interested in cases where both instruments depart from the ideal in some respect. In this section we describe, in turn, the various forms of instrument imperfection that may affect externality taxes and direct regulation, identifying some cases which we then model in subsequent sections.

The existing literature on imperfect externality-correcting taxes has observed that most of the available tax instruments are based on a proxy for the externality, such as the sale of a good, rather than the externality itself (Sandmo, 1976; Green and Sheshinski, 1976). To the extent that the tax base is not a perfect proxy for the externality, externality taxes involve inefficiency, arising from the imperfect targeting of the incentive. 
To explore this idea further we could distinguish between three forms of externality tax. Taxes may be imposed on

(1) the measured externality

eg a congestion charge levied per km travelled at the marginal congestion externality

(2) consumption of a good which generates the externality

eg a tax on motor fuel, set at a level to reflect the marginal congestion externality

(3) consumption of goods which are related to the externality-creating good

eg a tax on urban parking spaces, or a subsidy (negative tax) to public transport.

In analysing the use of commodity taxes to correct externalities, Green and Sheshinski (1976), Balcer (1980) and Wijkander (1985) refer to case (2) as a "direct" externality tax and case (3) as an "indirect" externality tax. The precise distinction being drawn is not always clear, and may amount to no more than that between a close proxy for the externality and weaker proxies. A sharper distinction could be drawn between a good which always generates the externality when consumed, and other goods which may be complements to or substitutes for consumption of this good.

A tax on measured emissions could, in principle, achieve the first-best if levied at the marginal external cost of each unit of emissions. But direct measurement of emissions and unit charging for the externality may be technically infeasible or excessively costly, and measured-emissions taxes are rare in practice. Even those which do exist may not be optimally-differentiated to reflect the precise marginal external cost associated with each unit of emissions.

Where the tax is not based directly on emissions or a perfect emissions proxy, there will tend to be inefficiency in the pattern of behavioural responses. Polluters will economise on use of the taxed commodity, but do not directly face an incentive to cut emissions. Costs may be incurred in reducing 
consumption in ways which do not reduce emissions. Likewise, possibilities for reducing emissions without reducing consumption will be ignored. In particular, there will be no incentive to use abatement technologies to alter the link between the taxed commodity and emissions. If we use the term "abatement" rather narrowly to refer to the use of such technologies, we can see that the inefficiency of taxes based on an emissions proxy rather than directly on emissions will consist in the fact that the first-best emissions tax leads to "consumption" and "abatement" responses, while the proxy encourages "consumption" responses alone.

Externality taxes levied on goods will typically differ from the first-best externality tax for one of three main reasons:

- It will frequently be much less costly to make use of existing tax bases (eg sales taxes or VAT) than to introduce wholly-new externality taxes. However, existing taxes are typically based on the value of sales, and this may be a poorer proxy for external costs than would be a separate excise tax on the quantity sold.

- Even where externality taxation can take the form of an excise tax on physical quantities of the good, and the design of the tax is unconstrained by the need for compatibility with existing tax arrangements, administrative costs may limit the extent to which the tax can be differentiated to reflect the level of externality associated with each use. Moderate levels of alcohol consumption may for example be fairly harmless while heavy drinking by some individuals generates large and progressively-increasing externalities. However, it may not be possible to identify those sales liable to generate large external costs, or to levy non-linear taxes on individual purchasers. A uniform tax may be employed, because an optimallydifferentiated tax would be excessively costly or infeasible.

- Some externality-generating consumption of a good may escape taxation because some sources of acquisition are not subject to domestic taxation. For example, goods may be 
directly imported by cross-border shoppers or purchased on an untaxed black market. The tax will then distort the choice between the taxed and untaxed sources of supply. Where a large tax generates a large deadweight loss, combining a lower tax and a (costly) regulation may be preferable to relying solely on a tax.

In brief, a tax can be imperfect because of imperfect targeting, insufficient differentiation or failure to avoid differentiation where it is not desirable. In each of these cases the question is whether there is a role for regulation supplementing a tax.

Regulations can be of many different kinds. Common examples in environmental policy are fixed quantitative limits on emissions or the mandatory use of abatement technologies. Regulating externalities generated by consumption typically uses rather different instruments, including various restrictions on sale or consumption. In many cases, consumption regulation can be interpreted as increasing the real cost of acquisition, or reducing the quality of the commodity consumed. Regulation restricts alcohol consumption by restricting the outlets where it can be sold and by limiting opening hours, adding inconvenience costs to the cost of consumer purchases. The utility derived from consumption may be reduced by restrictions on where and when goods can be consumed, in a way similar to a reduction in quality. Thus, for example, restrictions on smoking in offices and restaurants mean that cigarettes have to be consumed outside, and road traffic restrictions on driving in specific areas or at certain times reduce the convenience of car travel.

We can, in addition, draw a distinction between two types of consumption regulation, differing in how the impact on the externality arises. The first form of regulation works solely by reducing utility from each unit of the good consumed. The impact on the externality arises through the effect on the level of consumption alone - much the same response as would be achieved by using a consumption tax as an emissions proxy. The second form of regulation mandates the use of "abatement - in other words, requires consumers to bear an additional cost when consuming the good, that has the effect of reducing the externality from the units consumed. Typically regulation of this sort will have responses 
of two kinds - both "abatement" and "consumption" responses as discussed above. The scale of the consumption response relative to the abatement response will depend on the cost of abatement, and its relationship to the number of units consumed. This could in principle have various functional forms a fixed cost per consumer, a constant cost per unit consumed, or more complex relationships.

Imperfection in taxation is in a fundamental sense the justification for using regulation at all. One might think that if we can observe something sufficiently accurately to regulate it then we could tax it. If we can ban the sale of alcohol at particular times of the day, then we can, in principle, levy a tax on any such sales sufficient to reflect the externality involved, and this would appear to offer everything that the regulation can, with the added benefit of cost-reducing flexibility. In our view, the case for using regulation at all rests on the costs or impracticality of operating first-best externality taxes. While regulation might always be dominated by a theoretical first-best tax, the practically-available tax instruments may have inadequacies that make regulation preferable. Two issues, in particular, seem to be important.

- One is that externalities may often be non-linear in consumption, in various ways, and poorly approximated by uniform taxes on consumption. Thus, for example, requiring bars to close at a particular hour may limit public drunkenness, and while an increasing tax on each drink purchased - or even higher taxes on all drinks sold late at night - might in theory be able to achieve the same outcome with greater flexibility, neither could be implemented by modifying current excises, which tax alcoholic drinks well before the retail stage. Regulation may be better than a higher alcohol excise, even though neither is ideal. Time-of-day or purchaserspecific alcohol taxes would require much more complex administration, and would be exposed to various forms of avoidance, including resale, which could be hard to prevent. Restrictions increasing the real cost of acquiring the good may barely affect consumers who make small and infrequent purchases but have a substantial impact on large consumers and thus mimic a non-linear tax.

- The second attraction of regulation is that frequently a prohibition on some activity may be much cheaper to monitor and enforce than any other limit. Zero activity can be more readily 
monitored than any other level, in the sense that any activity demonstrates non-compliance. Enforcing any other limit than zero would typically require more complex investigation and record-keeping.

Nevertheless, the distinction between regulations and the use of taxes or other market-based instruments is not always clear-cut. A strict regulation may be imposed by making the installation of a certain abatement technology mandatory. A similar but less rigid policy would be to let installation be voluntary but to impose a tax on those who do not opt for the abatement technology. The advantage would be that the technology would not be adopted in cases where it is overly costly and socially undesirable but where the regulator would have sparse knowledge about costs. While the tax approach may appear to be the more efficient alternative it will also be more costly as, beyond monitoring the technology, one will have to determine the tax liability and collect taxes in each case while the regulation alternative will only require action to impose sanctions in the - conceivably few - instances of non-compliance.

\section{Imperfect Differentiation}

As discussed above, an ideal tax is one that taxes the externality directly according to the marginal external cost. Where the external cost is determined solely by consumption the amount consumed would be a perfect proxy for the externality, and a commodity tax would achieve the same allocation as an externality tax. However, total consumption may be a too crude measure. One may need to distinguish between consumption at different times, in different locations, by different people, and in various other circumstances as the external cost may vary according to all these characteristics. This section addresses the case where the tax cannot be differentiated according to this kind of variation.

Let a single consumer represent a homogeneous population. There are two consumption goods. Denote quantities by $c$ and $x$. The latter good can be consumed in two different activities labelled 1 
and 2, respectively (which may also be interpreted as locations or time periods). The quantities $x^{1}$ and $x^{2}$ generate negative externalities $e_{1}\left(x^{1}\right)$ and $e_{2}\left(x^{2}\right)$. Assuming a quasi-linear utility function ${ }^{1}$ we can express the utility of a consumer in the absence of regulation as

$U=c+f\left(x^{1}\right)+g\left(x^{2}\right)-e_{1}\left(x^{1}\right)-e_{2}\left(x^{2}\right)$

where the following properties are assumed: $f^{\prime}\left(x^{1}\right)>0, f^{\prime \prime}\left(x^{1}\right)<0, g^{\prime}\left(x^{2}\right)>0, g^{\prime \prime}\left(x^{2}\right)<0$, $e_{1}^{\prime}\left(x^{1}\right)>0, e_{1}^{\prime \prime}\left(x^{1}\right) \geq 0, e_{2}^{\prime}\left(x^{2}\right)>0, e_{2}^{\prime \prime}\left(x^{2}\right) \geq 0$.

The consumer is assumed to have a fixed income or endowment $w$. The cost of producing a unit of $x$ is $p$ which in a competitive market equilibrium equals the producer price. Let us assume that two externality-correcting instruments are available. One is a (uniform) tax on $x$, denoted $t$. The other is a regulation of activity 1 . The regulation, represented by a parameter $r$, reduces the utility derived from $x^{1}$, which we now write as $f\left(x^{1}, r\right)$. The underlying assumption is that the nature of the regulation is to degrade the circumstances in which the good is acquired or consumed. We assume that $f_{2}^{\prime}\left(x^{1}, r\right)<0$ and $f_{12}^{\prime \prime}\left(x^{1}, r\right)<0$ which means that tightening regulation will depress total as well as marginal utility of consuming the good in question. We may note that an abatement requirement would have the same effect to the extent that the loss of utility is incurred because the consumer is forced to spend resources on abatement but abatement would also have the further effect that it would diminish emissions for given consumption so there would be a shift in $e_{1}\left(x^{1}\right)$. We return to this issue in Section 5.

We can write the budget constraint of the consumer as

$$
w+T=c+(p+t)\left(x^{1}+x^{2}\right)
$$

where $\mathrm{T}$ is a lump-sum transfer used to recycle any government revenue to the consumer

\footnotetext{
${ }^{1}$ Assuming quasi-linearity is an innocuous assumption as, roughly speaking, substitution effects will prevail in optimal tax formulas as income effects tend to cancel out where tax revenue is returned to the tax payers via transfers.
} 
so that $T=t\left(x^{1}+x^{2}\right)$.

Allowing for regulation, we can write the utility function as

$V=c+f\left(x^{1}, r\right)+g\left(x^{2}\right)-e_{1}\left(x^{1}\right)-e_{2}\left(x^{2}\right)$.

The representative consumer, being a "small" agent in the market, maximises utility subject to the budget constraint, treating the externalities, the price and the government instruments as exogenous. The following first order conditions obtain

$f_{1}^{\prime}\left(x^{1}, r\right)=p+t$

$g^{\prime}\left(x^{2}\right)=p+t$

implying the demand functions

$x^{1}(p+t, r)$ and $x^{2}(p+t)$.

Simple comparative statics yield the effects of the instruments on the consumer's demand. It is straightforward to show that

$$
\begin{aligned}
& \partial x^{1} / \partial t=\partial x^{1} / \partial p=x_{p}^{1}=\frac{1}{f_{11}^{\prime \prime}\left(x^{1}, r\right)}<0 \\
& \partial x^{2} / \partial t=\partial x^{2} / \partial p=x_{p}^{2}=\frac{1}{g^{\prime \prime}\left(x^{2}\right)}<0
\end{aligned}
$$

For a change in $r$, a stricter regulation, we find

$$
\begin{aligned}
& f_{12}^{\prime \prime}\left(x^{1}\right)+f_{11}^{\prime \prime}\left(x^{1}\right) d x^{1} / d r=0 \\
& \partial x^{1} / \partial r=x_{r}^{1}=-\frac{f_{12}^{\prime \prime}\left(x^{1}\right)}{f_{11}^{\prime \prime}\left(x^{1}\right)}<0
\end{aligned}
$$

Allowing for the government instruments and making use of (2) and (3), we can express the consumer's utility as 
$V=f\left(x^{1}(p+t, r), r\right)+g\left(x^{2}(p+t)\right)+w-p x^{1}(p+t, r)-e_{1}\left(x^{1}(p+t, r)\right)-p x^{2}(p+t)-e_{2}\left(x^{2}(p+t)\right)$

Let us begin by considering the optimal tax and regulation in this framework. Suppose that initially welfare is maximised with respect to the tax rate implying the first order condition

$V_{t}=f_{1}^{\prime} x_{p}^{1}+g^{\prime} x_{p}^{2}-\left(p+e_{1}^{\prime}\right) x_{p}^{1}-\left(p+e_{2}^{\prime}\right) x_{p}^{2}=0$

and the second order condition

$V_{t t}<0$

where single and double subscripts are used to denote first and second derivatives, respectively. Invoking the first order conditions of the consumer's maximisation, we can write the first order condition for $t$ as

$t x_{p}^{1}(p+t, r)+t x_{p}^{2}(p+t)-e_{1}^{\prime} x_{p}^{1}(p+t, r)-e_{2}^{\prime} x_{p}^{2}(p+t)=0$

from which we get the formula

$t=\frac{e_{1}^{\prime} x_{p}^{1}(p+t, r)+e_{2}^{\prime} x_{p}^{2}(p+t)}{x_{p}^{1}(p+t, r)+x_{p}^{2}(p+t)}$

(12) is of the same form as the well-known weighted average formula of Diamond (1973) characterising the optimal uniform tax rate on activities that generate non-uniform external costs in the absence of regulation. Thus we have demonstrated that the weighted average formula for the tax holds also in this model where regulation is also present, but we note that regulation will normally change the weights. 
Turning to regulation and differentiating welfare with respect to the regulation parameter we obtain

$$
V_{r}=f_{1}^{\prime} x_{r}^{1}+f_{2}^{\prime}-\left(p+e_{1}^{\prime}\right) x_{r}^{1}=\left(t-e_{1}^{\prime}\right) x_{r}^{1}+f_{2}^{\prime}
$$

where the latter equation is due to (4)

Starting out from an unregulated situation, (stricter) regulation will be worthwhile if the sign of (13) is positive. For this to happen the marginal external cost of good $1, e_{1}^{\prime}$, must exceed the tax rate, $\mathrm{t}$, and the marginal real cost of regulation, $-f_{2}^{\prime}$, must not be too large. Since the tax rate is a weighted average of the marginal social costs of the two goods the good that should be regulated is the one with the larger marginal social cost.

Consider now how tighter regulation will affect the tax rate. Starting out from the first order condition, standard comparative statics yields

$$
V_{t t} \frac{d t}{d r}+\left(f_{1}^{\prime}-p-e_{1}^{\prime}\right) \frac{\partial x_{p}^{1}}{\partial r}+\left(\frac{\partial f_{1}^{\prime}}{\partial r}-e_{1}^{\prime \prime} x_{r}^{1}\right) x_{p}^{1}=0
$$

Making use of the condition $f_{1}^{\prime}=p+t$, it follows that $\frac{\partial f_{1}^{\prime}}{\partial r}=0$, and accordingly

$$
\begin{aligned}
& V_{t t} \frac{d t}{d r}+\left(t-e_{1}^{\prime}\right) \frac{\partial x_{p}^{1}}{\partial r}-e_{1}^{\prime \prime} x_{r}^{1} x_{p}^{1}=0 \\
& \frac{d t}{d r}=\left(e_{1}^{\prime}-t\right) \frac{\partial x_{p}^{1}}{\partial r} / V_{t t}+e_{1}^{\prime \prime} x_{r}^{1} x_{p}^{1} / V_{t t}
\end{aligned}
$$

We know that $e_{1}^{\prime}-t>0, V_{t t}<0, x_{r}^{1}<0, x_{p}^{1}<0$. Accordingly, the former term on the right hand side has the sign of $\frac{\partial\left(-x_{p}^{1}\right)}{\partial r}$. The partial effect of a steeper demand schedule is to decrease the tax rate. As we see from (12), the larger marginal external cost is then given less weight in the tax formula. Effects 
are opposite where regulation makes the demand curve flatter. Where the demand causing the more serious externality becomes more (less) price responsive the tax obviously becomes a more (less) efficient instrument for diminishing the externality. The latter term on the right hand side is strictly negative where the marginal external cost is increasing in consumption. This is natural as stricter regulation will discourage consumption and lower the marginal external cost and accordingly the externality-correcting tax.

We can sum up our results so far.

\section{Proposition 1}

Where a Pigouvian tax is supplemented by regulation it is the consumption causing the larger marginal external cost that should be regulated.

Where marginal external costs and the price responsiveness of demand schedules are constant tighter regulation leaves the tax rate unchanged.

Where the marginal external effect is increasing (non-decreasing) in consumption and regulation makes demand no more (less) price responsive the effect of stricter regulation is to lower the tax rate.

Where the marginal external cost is increasing in consumption and regulation makes demand more price responsive there are ambiguous effects on the tax rate.

In general, regulations can be of many types and it is hard to impose further restrictions on the $f$ function. However, it may be helpful to consider special cases. Assume first that

$f\left(x^{1}, r\right)=h\left(x^{1}\right)-r x^{1}$

$f_{1}^{\prime}\left(x^{1}, r\right)=h^{\prime}\left(x^{1}\right)-r=p+t$

$h^{\prime}\left(x^{1}\right)=p+t+r$ 
With this specification

$$
\begin{aligned}
& x_{p}^{1}=x_{r}^{1}=\frac{1}{f_{11}^{\prime \prime}}=\frac{1}{h^{\prime \prime}} \\
& x_{p p}^{1}=-\frac{h^{\prime \prime \prime}}{\left(h^{\prime \prime}\right)^{2}} x_{p}^{1} \\
& \frac{\partial}{\partial r} x_{p}^{1}=-\frac{h^{\prime \prime \prime}}{\left(h^{\prime \prime}\right)^{2}} x_{r}^{1}
\end{aligned}
$$

The characteristic of this case is that regulation has the same effect on demand as the price. We can conceive of a number of cases where this may be a plausible description. Suppose the regulation requires spending real resources in addition to the monetary expenses in order to acquire or consume the good. Then the cost of each unit of consumption will increase. Suppose the regulation is to lower speed limits on a road. Then the cost of travelling will increase in terms of time.

A common assumption in demand analysis is that $\mathrm{h} "{ }^{\prime \prime}>0$ and $x_{p p}^{1}>0 .{ }^{2}$ In this case a price increase and a stricter regulation will both make the demand schedule steeper and reduce the price responsiveness. Alternatively, a linear demand schedule is often considered where the slope of the demand schedule is constant.

Other specifications may treat the regulation as reducing the quality of the good. Conceivable specifications are $f\left(x^{1}, r\right)=h\left(x^{1} / r\right)$ or $f\left(x^{1}, r\right)=h(1-r) x^{1}$. In these cases the assumption that $h$ "'>0 implies that $r$ will have ambiguous effects on the slope of the demand schedule.

Now consider the full optimum where both the tax rate and the regulation have been optimised so that

\footnotetext{
${ }^{2}$ This might be suggested by the analogy with the expected utility function and the property of decreasing absolute risk aversion.
} 
$V_{t}=f_{1}^{\prime} x_{p}^{1}+g^{\prime} x_{p}^{2}-\left(p+e_{1}^{\prime}\right) x_{p}^{1}-\left(p+e_{2}^{\prime}\right) x_{p}^{2}=0$

$V_{r}=f_{1}^{\prime} x_{r}^{1}+f_{2}^{\prime}-\left(p+e_{1}^{\prime}\right) x_{r}^{1}=0$

Owing to (4)

$-\left(e_{1}^{\prime}-t\right) x_{r}^{1}(p+t, r)+f_{2}^{\prime}=0$

implying that $e_{1}^{\prime}-t>0$. Alternatively, we can write

$-\left(e_{1}^{\prime}-\bar{e}\right) x_{r}^{1}(p+t, r)+f_{2}^{\prime}=0$

where $\bar{e}$ is the weighted average in (12). It is important to note that $\bar{e}=t<e_{1}^{\prime}$ which confirms that regulation will be applied to the activity with the larger externality.

By standard comparative statics we can examine how the policy mix depends on the external effect. Consider now the case where marginal external costs are constant: $e_{1}\left(x^{1}\right)=\varepsilon^{1} x^{1}$ where $\varepsilon^{1}$ is a parameter. Differentiating the first order conditions with respect to $\varepsilon_{1}$ and denoting derivatives by means of a prime we find

$V_{t t} t^{\prime}+V_{t r} r^{\prime}=x_{p}^{1}$

$V_{r t} t^{\prime}+V_{r r} r^{\prime}=x_{r}^{1}$ 
To simplify, let us assume that third derivatives of $f$ and $g$ are zero and accordingly $x_{p}^{1}$ and $x_{r}^{1}$ are constant. Since $f_{1}^{\prime}\left(x^{1}, r\right)$ equals $p+t$, which is unaffected by $r$, it follows from (22) that $V_{r t}=0$.

$$
r^{\prime}=\frac{x_{r}^{1}}{V_{r r}}>0
$$

$$
t^{\prime}=\frac{x_{p}^{1}}{V_{t t}}>0
$$

since by second order conditions $V_{t t}<0$ and $V_{r r}<0$.

The tax rate is larger, and the optimal regulation is tighter the larger is the more serious externality. In a similar way we find by differentiating w.r.t. $\varepsilon_{2}$ that the tax rate will increase and the regulation is left unchanged in response to an increase in $\varepsilon_{2}$.

If instead we assume that the marginal external cost is increasing and there is a constant positive shift in the marginal external cost generated by $x_{1}$ regulation will become tighter while there are ambiguous effects on the tax rate. On the one hand the shift in the externality is an argument for a larger tax, but as the tighter regulation depresses the marginal external cost the net effect is indeterminate.

So far we have assumed that the regulation does not affect the demand for the unregulated good 2. Let us now consider the case of cross-effects so that a stricter regulation will shift some demand from good 1 to good 2. The utility function can be written

$$
U=c+F\left(x^{1}, x^{2}, r\right)-e_{1}\left(x^{1}\right)-e_{2}\left(x^{2}\right) .
$$


In general it is hard to know how the slopes of demand schedules will change and hence how the weights in (12) will change so let us consider the case of constant weights.

$$
t=\frac{x_{p}^{1}}{x_{p}^{1}+x_{p}^{2}} e_{1}^{\prime}+\frac{x_{p}^{2}}{x_{p}^{1}+x_{p}^{2}} e_{2}^{\prime}=w_{1} e_{1}^{\prime}+w_{2} e_{2}^{\prime}
$$

where $w_{1}$ and $w_{2}$ are the weights defined by the latter equation.

Cross effects on demand will imply that $x_{r}^{1}<0, x_{r}^{2}>0$, and plausibly the former change is larger in absolute value than the latter. (The reduced consumption in market 1 is not fully offset by increased consumption in market 2.)

$$
\frac{\partial}{\partial r} t=w_{1} e_{1}^{\prime \prime} x_{r}^{1}+w_{2} e_{2}^{\prime \prime} x_{r}^{2}
$$

The change in the tax rate will depend on the extent to which reduced demand for good 1 generates increased demand for good 2, on the weights, and on the changes in the marginal external costs. Circumstances that are conducive to a larger tax rate are that the marginal external cost curve of good 2 is steeper than that of good 1 , cross effects on demand are strong, and the weight of good 2 is large.

If regulating smoking in public places diverts smoking to other places and strongly drives up the marginal external cost there a larger tax is needed to reflect the larger external cost in the unregulated place. However, if the other place is not much affected or the regulation even induces people to give up smoking altogether the optimal tax will be lowered.

Beyond cross effects on demand, there may be cross effects on the external costs where the marginal cost is not constant. There may not only be an external cost from each activity but there may also be external costs which depend on the total consumption. The combination of a general external cost and activity specific externalities might be expressed as $\mathrm{e}\left(x^{1}+x^{2}\right)+e_{1}\left(x^{1}\right)+e_{2}\left(x^{2}\right)$. For instance, 
smoking may not only impose passive smoking on others at various times and places but there may be external costs owing to health effects which are related to the smoking record of a person independently of the circumstances in which the smoking took place. If there is no shifting of consumption from one activity to the other a restriction lowering consumption in one activity will then lower the marginal external cost in both activities and there is a case for lowering the tax. If there is some but less than fully offsetting increase in consumption in the other activity there will be opposing effects. The marginal "general" externality will decline but the other activity-specific externality, if present, will increase at the margin. Where restrictions on smoking in public induce people to smoke less altogether but more at home where there is no specific externality there is a case for lowering the $\operatorname{tax}$.

\section{A ban on an activity.}

A "soft" regulation of the type above is not always feasible. One might like to directly restrict the consumption of a good in a particular place, say restricting the amount of smoking, drinking, motorised traffic, burning coal, etc. One might like everybody to cut down consumption by thirty or fifty percent to alleviate the externality, but this restriction is hard to enforce where the level of consumption cannot be exactly monitored. The only regulation that can be enforced may be a ban, as the regulator will then only need to observe that somebody is consuming the good in order to know that the regulation is being violated. Subject to this constraint the cost benefit problem is whether cutting back the externality outweighs the loss of consumer's surplus inflicted by the ban (and the cost of the regulator). Suppose a ban on activity $i$ is socially desirable. Then activity $i$ will be abandoned and the tax is determined by equating it to the marginal external cost of activity $j$ (where $j \neq i$ ). A ban will raise or lower the tax depending on which activity that is being banned. This is not obvious. Even if activity $A$ causes the larger externality per unit, we don't know in which activity the external cost exceeds the consumer's surplus. (We suppose that this does not happen in both activities, which would justify banning the good altogether.) Thus even if a "soft" regulation will always be targeted at the activity with the larger marginal external cost, this need not be the case with a ban (even if we imagine it will often be the case). 


\section{Unwanted Differentiation - Tax Avoidance by Cross-border Shopping}

Sometimes there may be cases in which uniform taxation is difficult to implement, even when desirable, because the tax may be avoided in parts of the market. To fix ideas we shall consider a regime where the domestic tax may be avoided by purchasing the good in question abroad, but the example may be interpreted as representing more general cases. The important feature of the analysis is that the tax can be avoided at a real resource cost. In this sense our analysis is akin to the literature on risk-free but costly tax avoidance ${ }^{3}$. While cross-border shopping is chosen as a specific example it is also a case of major importance in many countries where consumers go abroad (or to other states in the US) to buy goods many of which are supposed to generate externalities (alcohol, tobacco, petrol).

Suppose that an amount $x$ of a good is purchased at home at a price $p+t$ and an amount $\mathrm{z}$ is purchased abroad at a retail price q and a (travel, etc.) cost $k(z)$, where $k^{\prime}>0, k^{\prime \prime}>0$. The budget constraint is

$$
w+T=c+(p+t) x+q z+k(z)
$$

where $\mathrm{w}$ is an exogenous income, and $T$ is a lump-sum transfer used to return any government revenue to the consumer and perceived as exogenous by the consumer. Hence, $T=t x$.

As before, our notion of regulation is that it imposes a real cost of consuming the externalitygenerating good. The utility function of a representative agent is

$U=c+f(x+z, r)=w+T-(p+t) x-q z-k(z)+f(x+z, r)$

The benefit derived from consuming $x+z$ is increasing in consumption and decreasing in regulation and the marginal benefit is assumed to be decreasing in consumption and in strictness of regulation, $r$. In mathematical terms $f_{1}^{\prime}>0, f_{2}^{\prime}<0, f_{11}^{\prime}<0, f_{12}^{\prime \prime}<0$.

The first order conditions of the consumer's maximisation are

\footnotetext{
${ }^{3}$ The idea is that by incurring a real resource cost, which is increasing in the amount of evasion/avoidance, a share of the tax base can be sheltered from taxation. See for example Boadway et al. (1994).
} 
$f_{1}^{\prime}(x+z, r)=q+k^{\prime}(z)$

$f_{1}^{\prime}(x+z, r)=p+t$

It follows from (35) and (36) that

$q+k^{\prime}(z)=p+t$

and

$z=z(p+t-q), \partial z / \partial t=1 / k^{\prime \prime}>0$

We also find from (36) that

$\frac{\partial(x+z)}{\partial t}=\frac{1}{f_{11}^{\prime \prime}}<0$

$\frac{\partial(x+z)}{\partial r}=\frac{-f_{12}^{\prime \prime}}{f_{11}^{\prime \prime}}<0$

The total consumption $x+z$ generates an externality expressed by the the external cost function $e(x+z)$. Allowing for the externality, and recalling that $T=t x$, social utility is

$w-p x-q z-k(z)+f(x+z, r)-e(x+z)=v(t, r)$

where the indirect utility function $v(t, r)$ is due to the fact that $x$ and $z$ are functions of $t$ and $r$ from (35) and (36). Maximising $v(t, r)$ w.r.t. the tax, we get the first order condition

$\partial v / \partial t=v_{t}=\left(-p+f_{1}^{\prime}(x+z, r)-e^{\prime}\right) \partial x / \partial t+\left(-q-k^{\prime}+f_{1}^{\prime}(x+z, r)-\mathrm{e}^{\prime}\right) \partial z / \partial t=0$

Making use of the first order conditions of the consumer we can simplify to obtain 
$v_{t}=\left(t-e^{\prime}\right) \partial x / \partial t-e^{\prime} \partial z / \partial t=0$

which we can reformulate as

$-\left(e^{\prime}-t\right) \partial(x+z) / \partial t-t \partial z / \partial t=0$.

Since $\partial z / \partial t>0$ and $\partial(x+z) / \partial t<0$ the immediate implication is that $t<e^{\prime}$. We can interpret $\mathrm{e}^{\prime}-t$ as the un-internalised part of the cost of consuming the good. Where the externality is only partially internalised $\left(\mathrm{t}<e^{\prime}\right)$ a tax discouragement of consumption will enhance welfare as reflected by the former term on the left hand side which we interpret as the marginal benefit of depressing consumption. The latter term on the left hand side is the distortion due to the cross-border shopping generated by the tax wedge, and we can interpret $t \partial z / \partial t$ as a marginal social cost of reducing $x+z$ by means of the tax.

The marginal cost per unit reduction of consumption is

$$
M C_{t}=\frac{t \partial z / \partial t}{-\partial(x+z) / \partial t}
$$

Consider now the marginal effect on social utility of using the regulation, when a tax is already in place.

$$
\partial v / \partial r=v_{r}=-\left(e^{\prime}-t\right) \partial(x+z) / \partial r+f_{2}^{\prime}(x+z, r)
$$

Similar to the discussion above, we can interpret the former term on the right hand side as the marginal benefit and $-f_{2}^{\prime}(x+z, r)$ as the marginal cost of the regulatory policy. 
The marginal cost per unit reduction of consumption is

$$
M C_{r}=\frac{f_{2}^{\prime}(x+z, r)}{\partial(x+z) / \partial r}
$$

Taking an arbitrary point of departure, the more efficient instrument at the margin is the one with the smaller marginal cost as defined above. Where regulation always inflicts a real resource cost on society, $f_{2}^{\prime}(x+z, r)<0$ for all feasible values of $r$, and we can conclude that if taxation is not used $M C_{t}=0<M C_{r}$. It follows immediately that it will never be optimal to rely solely on regulation. The explanation is simple. A small (infinitesimal) tax will imply a negligible distortion while even a small regulation will inflict a finite real cost on society. A conceivable caveat is that the introduction of a tax may involve an administrative cost so that a "small" tax is not costless. Such a cost might deprive the tax of its edge over regulation but only if adopting the regulation is less costly in terms of administration.

A further implication is that at a very low level of government intervention, the externality-alleviating policy will rely solely on taxation. Indeed this would be the case where the externality itself is minor.

\section{Proposition 2}

Where a tax and a costly regulation may coexist it will never be optimal to rely solely on regulation. At a sufficiently modest level of intervention the tax is the only instrument deployed at the optimum.

Where there is a major externality, calling for extensive intervention, it is likely to be efficient to deploy both instruments. The optimality condition will require $M C_{t}=M C_{r}$.

Where $t$ is "large" any change in $t$ will take place from a distorted point of departure and there is conceivably a sizeable marginal cost associated with using the tax alone to mitigate the externality. The tax imperfection due to partial enforcement implies that it is not only the regulation that entails a 
real cost. We note that where the tax (and price) response of cross-border shopping is (close to) constant the numerator of (45) is obviously increasing in $t$. If the demand schedule becomes steeper as demand declines with increasing price this effect is being reinforced. (We discuss these properties further below.) Unless the marginal cost of regulation is overly large, gradually increasing the tax will take us to a point where the marginal cost of taxation no longer falls short of the marginal cost of regulation, and efficiency requires that the regulation kicks in.

A further question is how one would like to combine the two instruments for diminishing consumption beyond the level where regulation is adopted. The combination will then be determined by two conditions: $\mathrm{t}$ and $\mathrm{r}$ should be chosen such that the desirable amount of consumption $(x+z)$ is achieved and marginal costs (defined by (45) and (47)) should be equated. How marginal cost curves are affected by changes in $r$ ant $t$ will then be crucial for the optimal mix. Where both marginal costs increase as a stricter policy is applied both instruments will be used more intensively but other cases are conceivable. Assume that $M C_{r}$ is constant while $M C_{t}$ is increasing in $t$ but is unaffected by $r$. Then any further reduction in consumption beyond the point where $r$ is introduced will be achieved by increasing $r$ and keeping $t$ unchanged. Otherwise $M C_{t}$ would be pushed above $M C_{r}$. Where $M C_{r}$ is constant but the effects of both $t$ and $r$ are to increase $M C_{t}$ the $r$-instrument will be used to depress consumption beyond the threshold where regulation kicks in while the use of $t$ will be scaled down as stricter regulation is imposed.

Consider now the case where initially the tax is the only instrument in use. We may then ask how introducing regulation will affect the tax-setting. Note that the difference from the paragraph above is that the consumption level is set optimally conditional on the available tax instruments. Where the tax is used optimally we know from (43) that

$v_{t}=\left(t-e^{\prime}\right) \partial x / \partial t-e^{\prime} \partial z / \partial t=0$

and the corresponding second order condition is $v_{t t}<0$. We note from (37) that $\mathrm{z}$ is independent of $r$. Differentiating wrt $r$ we get 
$v_{t t} \frac{d t}{d r}+\left(t-e^{\prime}\right) \frac{\partial}{\partial r} \partial x / \partial t-e^{\prime \prime} \frac{\partial}{\partial r}(x+z) \frac{\partial}{\partial t}(x+z)=0$.

The expression consists of three main terms. Due to the second order condition $v_{t t}<0$. We have observed that $t-e^{\prime}<0 . \frac{d}{d r} \partial x / \partial t$ may have either sign. $e^{\prime \prime} \geq 0$, and the last term (including the minus sign) is zero or negative. We note that $e^{\prime \prime}>0$ is conducive to making $\mathrm{dt} / \mathrm{dr}$ negative. The interpretation is straightforward. Tighter regulation will diminish the emission and lower the marginal external cost implying that there is less need for the externality tax. When regulation is tightened $\frac{d}{d r}(-\partial x / \partial t)<(>) 0$ is conducive to making $d t / d r<(>) 0$. It follows that where $e^{\prime \prime}=0 d t / d r<0$ if $\frac{d}{d r}(-\partial x / \partial t)<0$. Likewise $d t / d r>0$ where $\frac{d}{d r}(-\partial x / \partial t)>0$. The crucial factor is whether regulation makes domestic demand more or less price responsive. To simplify further consider the case where $\partial z / \partial t$ is constant (corresponding to a quadratic cost function $k(z)$, which is in fact a common assumption in the literature on cross-border shopping). Then $\frac{d(-\partial x / \partial t)}{d r}=\frac{d(-\partial(x+z) / \partial t)}{d r}$. Where consumption becomes less sensitive to a price increase when there is stricter regulation the tax is used to a lesser extent when stricter regulation is imposed. It is commonplace to draw the demand schedule so that a price change has a smaller impact on demand at lower levels of consumption. If a regulationinduced decline in demand has the same effect we would have a case for a lower tax. In general we cannot rule out the opposite case. Where there is a linear demand schedule $(\partial(x+z) / \partial t$ is constant $)$ regulation will have no impact on the optimal tax unless $e^{\prime \prime}>0$.

\section{Proposition 3}

Let the tax be the only instrument optimally in use. Then introducing a marginal regulation has the following partial effects:

i. a lower (higher) tax where regulation makes domestic demand less (more) sensitive to a tax increase,

ii. a lower tax where the marginal external cost is increasing in consumption. 
Where demand is more sensitive to price the tax becomes a more efficient instrument for diminishing the quantity consumed and the associated externality. The externality can then be depressed more without creating a larger tax wedge between sources of supply.

\section{Some Further Issues}

So far in this paper we have confined our attention to cases where the sole objective of policy is the efficient control of an externality. Where the tax raises revenues these have no social value, and can be returned to individuals in lump-sum payments. The extensive "double dividend" literature ${ }^{4}$ has, however, emphasised the value of the revenues derived from externality taxes, which can reduce the need for revenues from other tax instruments. Externality taxes may then be set with two objectives in mind - both alleviating externality distortions, and contributing to efficient revenue-raising. How far does the recognition of this second objective affect the optimal policy mix of imperfect tax and imperfect regulation?

For considering these issues a natural starting point is the literature on the role of commodity taxes in an efficient revenue system. It is well known from the literature that where a distortionary income tax is used to raise revenue, a commodity tax (or commodity subsidy) may in some circumstances enhance welfare by alleviating the distortions associated with the income tax ${ }^{5}$. Where differential taxation of people with different, but unobservable, earnings capacity is desirable for distributional reasons the income tax must be designed subject to the self-selection constraint that the more productive agents do not mimic the less able, and distortions are mitigated by softening this constraint. The alleviation naturally comes at a cost since differential commodity taxation distorts the choice of consumption

\footnotetext{
${ }^{4}$ See Bovenberg and Goulder (2002) for an overview

${ }^{5}$ An important insight underpinning this literature is the observation that a commodity tax only adds to the fiscal possibilities offered by an income tax to the extent that it taxes goods at different rates; a uniform tax on all consumption is equivalent to a uniform tax on income.
} 
bundle. A number of papers ${ }^{6}$ have discussed this issue making various assumptions about the income tax, and have shown that assumptions about the structure of consumer preferences are crucial for the use of commodity taxes to enhance the efficiency of revenue-raising. The key issue is the relationship between commodity demands and labour supply. Where these interact, then, roughly-speaking, commodities that are related to leisure should be taxed at high rates while work-related commodities should be taxed less (or subsidised) in order to mitigate labour supply distortions. These policy rules may, however, need to be adjusted once the role of some commodities in generating externalities is recognised $^{7}$. Pirtillä and Tuomala (1997) show that, where environmental quality and leisure are complements, a deterioration in environmental quality can alleviate the self-selection constraint on income taxation, suggesting that the externality tax might then be set lower than would be optimal in the absence of revenue-raising and distributional considerations.

This strand of literature confines its attention to optimal tax analysis and does not consider the use of regulation. Since the objective of minimising the distortionary cost of revenue-raising prevents the commodity tax from being tailored perfectly to the Pigouvian objective of minimising external costs, it might seem that the addition of a further instrument in the form of regulation would ease the constraint on the attainment of both objectives. This may conceivably be the case with certain forms of regulation. But with the type of regulation considered above - which acts to increase the costs of obtaining each unit consumed - the additional instrument is not likely to be of help ${ }^{8}$. The reason is that it is the real choice of consumption bundle that matters. It is the encouragement or discouragement of the consumption of specific commodities that affects labour supply. Whether this is achieved by using taxes or regulation is immaterial to the impact on the self-selection constraint on income taxation, but there may be a difference in the cost of achieving the outcome. The main social cost of taxation is to distort the consumption bundle but regulation will do the same. Beyond these similar effects,

\footnotetext{
${ }^{6}$ For instance Corlett and Hague (1953), Atkinson and Stiglitz (1976), Christiansen (1984).

${ }^{7}$ Crawford et al (2009), in a paper for the Mirrlees Review, discuss which (positive or negative) commodities taxes that should supplement income taxes based also on empirical findings. The authors note that the "list of commodities includes some associated with pollution and other externalities, which might have implication for tax rates tempering those arising from the issues of preference structure addressed here".

${ }^{8}$ We develop this formally in Christiansen and Smith (2008).
} 
regulation is likely to impose a larger burden on consumers as it works by inflicting a loss of utility for any given consumption bundle as discussed above. It follows that this kind of regulation will be inferior to the tax instrument, and will achieve no reduction in the distortionary costs of income taxation.

\section{Conclusions}

Information asymmetries and costs of administration may give rise to imperfections in both externality taxes and direct regulation. Used alone, neither instrument may be capable of achieving the most efficient reduction in external costs, and a more efficient outcome may be achieved by combined use of multiple instruments. This paper looks at the economic issues which arise when externality taxes and direct regulation are used in parallel. It explores the properties of two simple models of imperfect tax and imperfect regulation, reflecting different form of imperfection in the tax instrument.

The focus of the paper is on externalities arising from individuals' consumption decisions. A number of such externalities are affected by the kinds of instrument inefficiency we describe. Taxes on the sale of alcoholic drinks or tobacco products, for example, can only roughly approximate the externalities generated by their consumption. Likewise the available forms of regulation, such as the recent ban on smoking in public places in many European countries, are not precisely targeted to the underlying external costs.

Regulation may affect consumption behaviour in a number of ways. We suggest that for a number of consumer externalities it may be useful to think of regulation as an increase in the cost to consumers of obtaining the good (for example, where the sale of alcoholic drinks is limited to a small number of outlets). Regulation thus has effects which are similar to - but not equivalent to - an increase in price. It will be seen that the representation of regulation here differs sharply from the emission limits or technology mandates typically considered when analysing the regulation of industrial emissions. 
Section 3 considered a case where an externality tax cannot be adequately differentiated to reflect differences in the external costs from different units consumed. Costs may differ between individuals, or between consumption in different contexts, and yet the tax is constrained to be uniform. We show that in this situation the outcome can be improved by direct regulation of consumption generating the larger external cost. The optimal externality tax rate in this context takes the same form as the wellknown weighted average formula of Diamond (1973). How it is affected by the addition of regulation will depend on how marginal external costs and the price responsiveness of demand vary with consumption. Where these are constant, tighter regulation has no effect on the optimal tax, but if the marginal external effect is increasing in consumption and if regulation does not increase the priceresponsiveness of demand for the regulated activity, adding regulation reduces the optimal externality tax rate.

Section 4 considered a contrasting case where the tax exhibits undesirable differentiation - for example where some consumption escapes the externality tax, by being purchased in low-tax countries abroad or on the black market. Where this happens, an externality-motivated commodity tax will distort the choice between different sources of supply and the resulting excess burden will be increasing in the tax rate. We show that the optimal policy mix will depend on the scale of intervention required. Where there is a major externality it will, as before, be optimal to deploy both instruments, set at a level to equate the marginal cost per unit reduction in consumption from each instrument. However, although both instruments are imperfect, combined use will not always be optimal. We demonstrate that in cases where the externality is small, it will be efficient to control externality effects using the tax alone, and it will never be optimal to rely solely on regulation. The intuition for this result is straightforward: regulation always inflicts a finite real resource cost on society, while a small (infinitesimal) tax involves negligible distortion.

We then consider the implications of introducing regulation, starting from a situation where the externality is controlled through the use of a tax alone. In this situation, the addition of regulation may 
raise or lower the optimal tax. As before, these effects will depend on how marginal external costs and the price responsiveness of demand vary with consumption. Adding regulation will reduce the optimal tax where regulation reduces the sensitivity of demand to the tax, and/or where the marginal external cost is increasing in consumption.

Our models have in common that using the tax to internalise an externality is costly because it it is distortionary in some other respect. In the former model, increasing the tax to alleviate the more serious externality will over-internalise the weaker externality. In the latter model a larger tax will better internalise the externality but will increase the locational distortion. We note that in both models sensitivity of demand is crucial to the effect of tighter regulation on the optimal externality tax In the first model the tax is a more (less) efficient instrument for diminishing the externality where the demand causing the more serious externality becomes more (less) price sensitive in response to the regulation. In the second model more price responsive domestic demand makes the tax a more efficient instrument for diminishing the quantity consumed and the associated externality. With larger sensitivity the externality can be depressed more without creating a larger tax wedge between sources of supply.

\section{References}

Atkinson, A. B. and Stiglitz J. E. (1976), The Design of Tax Structure: Direct versus Indirect Taxation, Journal of Public Economics 6, 55-75.

Balcer, Y., (1980), Taxation of Externalities: Direct versus Indirect, Journal of Public Economics 13, 121-129.

Boadway, R., Marchand M. and Pestieau, P. (1994), Towards a Theory of the Direct-Indirect Tax Mix, Journal of Public Economics 55, 71-88.

Bovenberg, A.L. and Goulder, L.H., (2002), Environmental Taxation and Regulation, in A. J. Auerbach and M. Feldstein (eds.), Handbook of Public Economics, Elsevier, New York, 
$1471-1545$.

Christiansen, V. (1984), Which Commodity Taxes Should Supplement the Income Tax? Journal of Public Economic 24, 195-220.

Christiansen V. and S. Smith (2009), Imperfect Externality-Correcting Taxes and Regulation when Revenues Matter. Mimeo.

Cnossen, S. (2005), Theory and Practice of Excise Taxation. Smoking, Drinking, Gambling, Polluting, and Driving, Oxford University Press, Oxford.

Corlett, W. J. and Hague, D. C. (1953), Complementarity and the Excess Burden of Taxation, Review of Economic Studies 21, 21-30.

Crawford, I., Keen, M. and Smith, S. (2009), "Value Added Tax and Excises" in Institute for Fiscal Studies (ed) Dimensions of Tax Design. Background papers for the Mirrlees Review of the UK Tax System, Oxford University Press, Oxford.

Diamond, P.A. (1973), Consumption Externalities with Imperfect Corrective Pricing, Bell Journal of Economics 4, 526-38.

Eskeland, G.S. (1994), A Presumptive Pigouvian Tax: Complementing Regulation to Mimic an Emissions Fee, World Bank Economic Review 8, 373-94.

Fullerton, D. and Wolverton, A. (1999), The Case for a Two-part instrument: Presumptive Tax and Environmental Subsidy, in A Panagariya, P.R. Portney and R. M. Schwab (eds), Environmental and Public Economics. Essays in Honor of Wallace E. Oates, Edward Elgar, Cheltenham.

Green, J. and Sheshinski, E. (1976), Direct versus Indirect Remedies for Externalities. Journal of Political Economy 84, 797-808.

Hoel, M., (1998), Emission Taxes versus Other Environmental Policies, Scandinavian Journal of Economics 100, 79-104.

Hoel, M. (1997), International Coordination of Environmental Taxes, in C. Carraro and D. Siniscalco (eds.), New Directions in the Economic Theory of the Environment, Cambridge University Press, Cambridge,105-146. 
Innes, R. (1996), Regulating Automobile Pollution under Certainty, Competition and Imperfect Information. Journal of Environmental Economics and Management 31, 219-239.

Mandell, S. (2004), Optimal Mix of Price and Quantity Regulation under Uncertainty. Stockholm University Research Papers in Economics, 204:12

Pirttilä, J. and Tuomala M. (1997), Income Tax, Commodity Tax and Environmental Policy International Tax and Public Finance 4, 379-393

Roberts, M. J. and Spence, M. (1976), Effluent Charges and Licenses under Uncertainty", Journal of Public Economics 5, 193-208.

Sandmo, A., (1976), Direct versus Indirect Pigovian Taxation. European Economic Review 7, 337349.

Sandmo, A., (2000), The Public Economics of the Environment, Oxford University Press, Oxford.

Weitzman, M. L. (1991), Prices vs. Quantities, Review of Economic Studies 41, 477-91.

Wijkander, H., (1985), Correcting Externalities through Taxes on Subsidies to Related Goods, Journal of Public Economics 28, 111-125. 